\title{
Amphetamine, Cocaine, and Fencamfamine: Relationship between Locomotor and Stereotypy Response Profiles and Caudate and Accumbens Dopamine Dynamics
}

\author{
Ronald Kuczenski, David S. Segal, and Moacyr L. Aizensteina \\ Department of Psychiatry, University of California at San Diego, La Jolla, California 92093
}

Using in vivo microdialysis, the caudate and nucleus accumbens dopamine (DA) responses to the psychomotor stimulants amphetamine (AMPH), cocaine (COC), and fencamfamine (FCF) were evaluated in rats concurrent with characterization of their behavioral response profiles. Doses of each stimulant that produced either enhanced liocomotion or a prolonged period of intense focused stereotypies were examined to evaluate the quantitative relationships between stimulant-induced behaviors and changes in DA dynamics and to test the hypothesis that a balance between mesostriatal and mesolimbic DA activity contributes to the appearance of specific stimulant-induced behaviors.

Although $10 \mathrm{mg} / \mathrm{kg} \mathrm{COC}$ and $1.7 \mathrm{mg} / \mathrm{kg}$ FCF promoted levels of locomotor activity substantially greater than $0.5 \mathrm{mg} /$ $\mathrm{kg} \mathrm{AMPH,} \mathrm{the} \mathrm{magnitude} \mathrm{of} \mathrm{the} \mathrm{DA} \mathrm{increases} \mathrm{in} \mathrm{both} \mathrm{caudate}$ and accumbens were markedly less than was obtained following AMPH. Thus, stimulant-induced locomotion appears to be dissociated from the quantitative DA response in both brain regions. This behavioral/DA dissociation was also apparent at higher doses of AMPH (2.5 mg/kg), COC (40 mg/ $\mathrm{kg}$ ), and FCF (6 $\mathrm{mg} / \mathrm{kg})$, doses that promoted a behavioral pattern that included a prolonged period of intense stereotypy. Indeed, the regional DA responses to these high doses of COC and FCF were substantially less than the response to $0.5 \mathrm{mg} / \mathrm{kg}$ AMPH. Furthermore, there were no differences in the ratio of the caudate and accumbens DA responses as a function of dose for any of the three drugs. Thus, the balance between the regional DA activation does not appear to regulate the expression of the behavioral response.

Additionally, the effects of these stimulants on regional DA metabolite concentrations were compared. The results indicate that AMPH promoted an identical pattern of effects on caudate and accumbens DA metabolites, suggesting that similar mechanisms govern the dynamics of DA in response to AMPH in both brain regions. In contrast, the DA uptake blockers promoted some region-specific effects on DA metabolites that may be due to regional differences in the DA metabolism and rates of impulse flow.

Received Dec. 18, 1990; revised Mar. 27, 1991; accepted Apr. 11, 1991.

This work was supported by U.S. Public Health Service Grants DA-04157 and DA- 01568 and by Research Scientist Award MH-70183 to D.S.S. We thank Cathy Halkovich and Skip McCunney for their excellent technical assistance.

Correspondence should be addressed to Dr. Kuczenski, Department of Psychiatry, UCSD, La Jolla, CA 92093-0603.

a Visiting CAPES/Fulbright Fellow from the Setor de Psiocofarmacologia, Departmento de Farmacologia, Instituto de Ciencias Biomedicas da Universidade de Sao Paulo, 05508 Sao Paulo, Brazil.

Copyright (c) 1991 Society for Neuroscience 0270-6474/91/112703-10\$03.00/0
Converging evidence suggests that the mesostriatal dopaminergic pathway plays a crucial role in the stereotyped behaviors induced by amphetamine (AMPH) and AMPH-like stimulants (Creese and Iversen, 1974; Kelly, 1977; Cole, 1978). Consistent with this evidence, results obtained using the microdialysis technique have shown that AMPH promotes a dose-dependent increase in the extracellular concentration of dopamine (DA) in caudate (Zetterström et al., 1983; Hernandez et al., 1987; Sharp et al., 1987; Carboni et al., 1989). However, our findings indicate that there is a dissociation between the expression of specific stimulant-induced behaviors and the quantitative aspects of the caudate dopaminergic response to AMPH (Kuczenski and Segal, 1989). One possible explanation for the absence of a close relationship between behavior and caudate DA is that the mesolimbic DA system also contributes to the stimulant response, particularly with regard to the locomotor activating effects of these drugs (Kelly and Iversen, 1976; Sessions et al., 1980; Swerdlow et al., 1986). In fact, we have suggested that the relative activation of the mesostriatal and mesolimbic DA systems may play a significant role in determining the expression of the AMPH behavioral profile (Segal and Kuczenski, 1987). To evaluate this hypothesis, we have extended our earlier studies by concurrently assessing the caudate and accumbens DA response to AMPH using multiple-site microdialysis in freely moving animals.

Other psychomotor stimulants, such as cocaine (COC) and fencamfamine (FCF), produce behavioral effects like AMPH in humans and animals. However, whereas AMPH facilitates DA transmission through enhanced release of the transmitter $(\mathrm{Ku}$ czenski, 1983), COC and FCF are alleged to act primarily through blockade of DA uptake (Kuczenski, 1983; Seyfried, 1983; DeLucia et al., 1984; Nicolaysen and Justice, 1988; Carboni et al., 1989). Therefore, to obtain converging evidence regarding the role of the mesolimbic and mesostriatal DA systems in the stimulant response, the effects of COC and FCF were compared to the AMPH-induced biochemical and behavioral alterations. The results presented below further suggest the absence of a simple relationship between the expression of specific components of the stimulant-induced behavioral profile and the quantitative features of the caudate or the accumbens DA response pattern, or of their relative degrees of activation.

\section{Materials and Methods}

Methodology. Rats obtained from Charles River Laboratories (275-300 $\mathrm{gm}$ ) were maintained four per cage on a 12 -hr reversed light/dark cycle (lights on at 6:00 P.M.) under standard laboratory conditions, with ad libitum access to food and water for 2 weeks prior to manipulation. Animals were then stereotaxically implanted with guide cannulas using 


\section{Caudate Putamen}

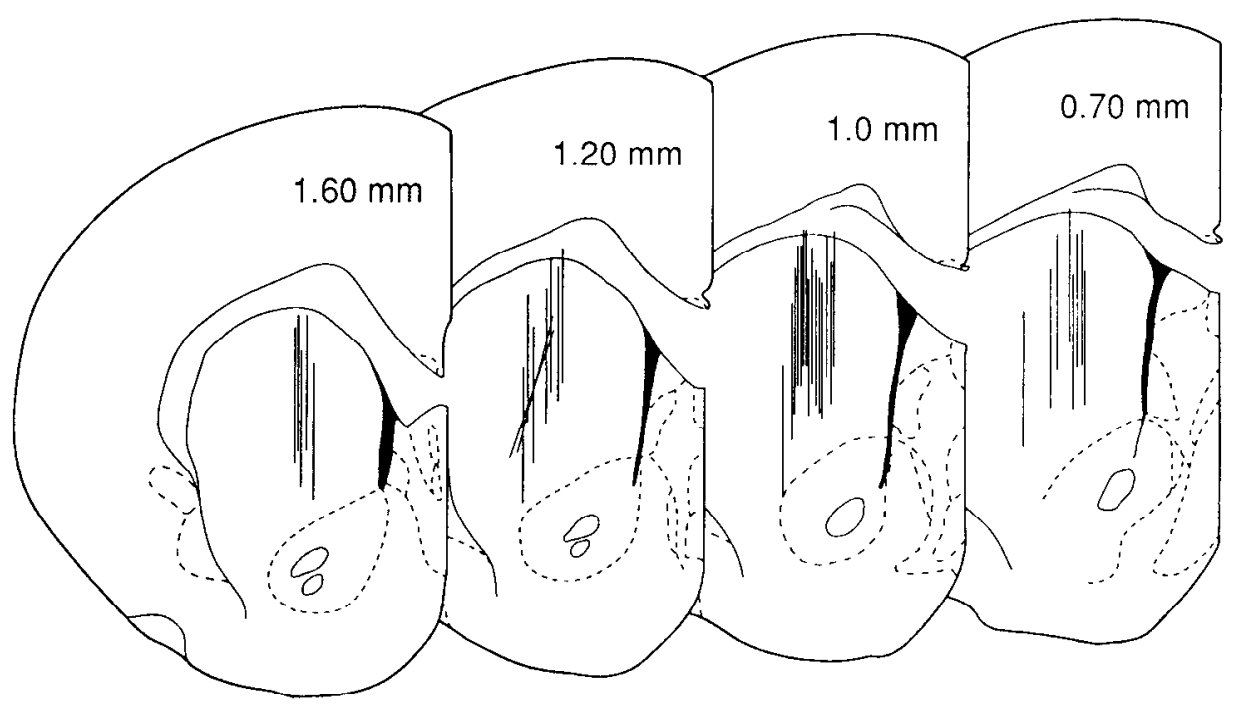

Nucleus Accumbens

Figure 1. Composite representation of the location of the active surface of dialysis probes in caudate-putamen (upper) and nucleus accumbens (lower). The drawings are based on the atlas of Paxinos and Watson (1986). The distance rostral from bregma is indicated on each drawing.

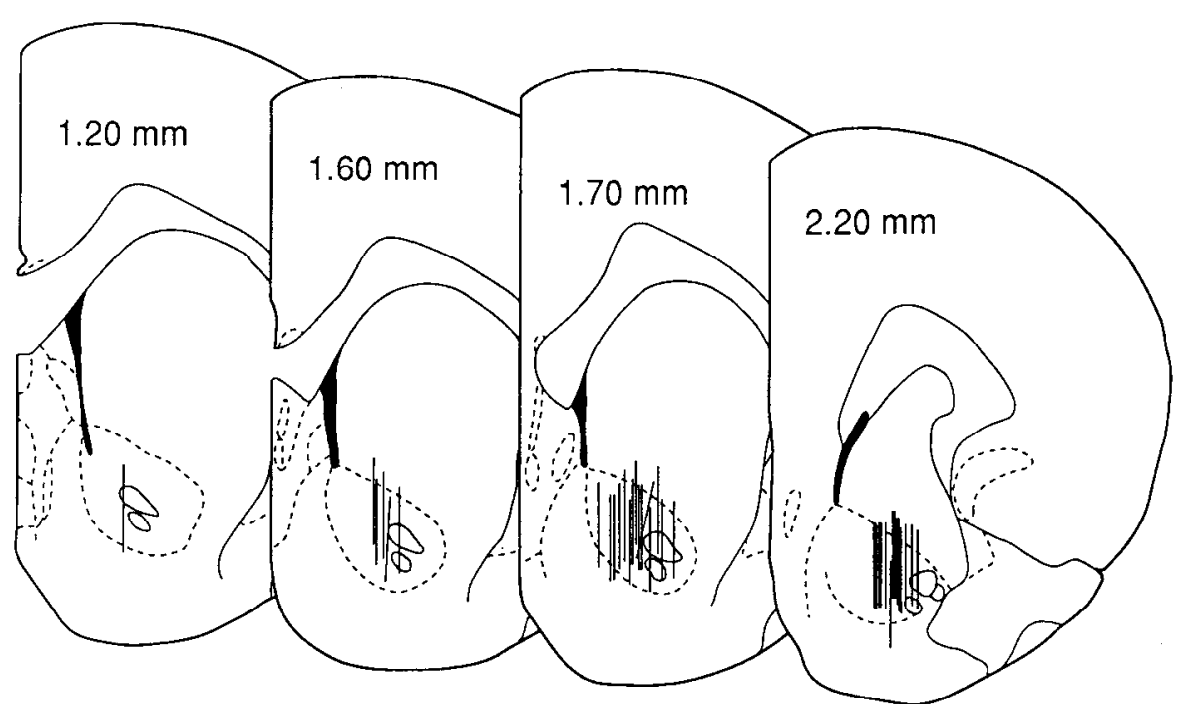

pH 3.8. The tubing and swivel were supported by a counterweight assembly, thereby allowing unrestricted movement by the rat, and samples were collected outside the experimental chamber to avoid disturbing the animal. Individual probe recoveries, which ranged from $1.5 \%$ to $3.5 \%$, were estimated by sampling a standard DA/3,4-dihydroxyphenylacetic acid (DOPAC) solution in vitro.

The behavioral chambers, described in detail elsewhere (Segal and Kuczenski, 1987), were soundproofed and were maintained on a reverse light/dark cycle, with constant temperature and humidity. Animals had continuous access to food and water. All drugs were administered at approximately 10:00 A.M. Dialysates were collected remote from the animal, outside of the chamber, and, with the exception of drug administration, the rat was not disturbed until the end of sample collection. Behavioral measures, including crossovers, rearings, and contacts with the food and water containers, were automatically collected through computer-assisted techniques. Animals were also videotaped to allow observational rating of behavior as described previously (Segal and nected to a fluid swivel. Dialysate was collected through glass capillary tubing into vials containing $10 \mu \mathrm{l}$ of $50 \%$ methanol, $0.5 \mathrm{M}$ sodium citrate, 
Table 1. Caudate and accumbens dialysate concentrations

\begin{tabular}{lllll} 
Region & DA & DOPAC & HVA & 5HIAA \\
\hline Caudate & $21.4 \pm 1.5$ & $7104 \pm 374$ & $5739 \pm 285$ & $2074 \pm 112$ \\
Accumbens & $12.8 \pm 1.3^{* * *}$ & $9171 \pm 716^{* *}$ & $4785 \pm 316^{* *}$ & $2500 \pm 147^{* * *}$
\end{tabular}

Data are expressed (in $\mathrm{nM}$ ) as mean \pm SEM.

$* *, p<0.01{ }^{* * *}, p<0.001$ when compared to corresponding caudate values (paired $t$ tests); $n=42$.

Kuczenski, 1987). After drug administration, the percentage of time during which the animal engaged in focused sniffing, repetitive head movements, or oral stereotypies was recorded. At the end of the experiment, each animal was perfused with formalin for histological verification of probe placements.

Biochemistry. Dialysate samples $(40-50 \mu \mathrm{l})$ were collected every 20 min, and DA, DOPAC, homovanillic acid (HVA), and 5-hydroxyindoleacetic acid (5HIAA) were assayed in $40-\mu$ l aliquots by HPLC with electrochemical detection (HPLC-EC). The HPLC-EC consisted of a $100 \times 2.3 \mathrm{~mm}$ ODS-C18 $3-\mu \mathrm{m}$ column (ESA) maintained at $35^{\circ} \mathrm{C}$. Mobile phase $\left(0.08 \mathrm{M}\right.$ citric acid, $7 \%$ methanol, $0.1 \mathrm{mM} \mathrm{Na}_{2}$ EDTA, and $0.8 \mathrm{~mm}$ octane sulfonate adjusted to $\mathrm{pH} 3.7-4.2$ ) was delivered at $1 \mathrm{ml} /$ min by a Waters model 510 pump. Amines were detected with a Waters 460 detector with glassy carbon electrode maintained at $+0.65 \mathrm{~V}$ relative to an $\mathrm{Ag} / \mathrm{AgCl}$ reference electrode. Concentrations were estimated from peak areas using a Waters Maxima 820 data station. Although the exact relationship between dialysate concentration and actual extracellular transmitter content is not clear (Wages et al., 1986; Church and Justice, 1987; Benveniste et al., 1989), substances in the dialysates were corrected for individual probe recoveries and are presented as concentration to allow for meaningful comparisons to other data in the literature. All drug-induced neurochemical effects were first statistically evaluated using a repeated-measures ANOVA, and all post hoc comparisons between groups utilized $t$ tests with Bonferroni correction.

Drugs. S(+)-AMPH (National Institute on Drug Abuse [NIDA]), COC $\mathrm{HCl}$ (NIDA), and FCF $\mathrm{HCl}$ (Aldrich) were dissolved in saline and injected in a volume of $1 \mathrm{ml} / \mathrm{kg}$ body weight. Doses refer to weight of free base. COC and FCF were administered intraperitoneally, and AMPH was administered subcutaneously.

\section{Results}

A composite representation of the location of the active surface of each dialysis probe is presented in Figure 1. Only animals for which both the caudate and accumbens probes were located in the target region and both remained functional throughout the experiment $(N=42)$ were included in the data analysis.

The median value of the three dialysate samples immediately preceding drug injection was selected as baseline for DA and its metabolites. No significant differences in baseline concentrations were observed among groups receiving different stimulant treatments, and therefore all animals were combined to compare regional baseline levels of DA and the metabolites (Table 1). Comparisons revealed significantly higher caudate concentrations of DA and HVA and significantly lower caudate concentrations of DOPAC and 5HIAA.

\section{Response to low doses of stimulants}

Based on preliminary studies (data not shown), a dose for each of the three stimulants was selected that promoted locomotor activation in the absence of focused stereotypies. The effects of $0.5 \mathrm{mg} / \mathrm{kg} \mathrm{AMPH}, 10 \mathrm{mg} / \mathrm{kg} \mathrm{COC}$, or $1.7 \mathrm{mg} / \mathrm{kg}$ FCF on locomotion of animals undergoing concomitant caudate and accumbens dialysis are summarized in Table 2. At these doses, AMPH-induced horizontal locomotion was significantly lower than both COC and FCF. Videotaped observations confirmed that none of the drugs promoted focused stereotypies.

The caudate and accumbens dopaminergic responses to the three stimulants are presented in Figures 2-4. Consistent with our previous results (Kuczenski and Segal, 1989; Kuczenski et al., 1990), $0.5 \mathrm{mg} / \mathrm{kg}$ AMPH maximally increased DA concentrations in caudate dialysates to $242 \mathrm{nM}(980 \%$ of baseline) and decreased DOPAC and HVA concentrations by $57 \%$ and $37 \%$, respectively. Peak DA concentrations were achieved during the first 20-40 min after drug administration. In the accumbens, the dopaminergic response pattern to AMPH was similar. AMPH increased accumbens DA concentrations to $131 \mathrm{nM}(860 \%$ of baseline) and decreased DOPAC and HVA by $58 \%$ and $39 \%$, respectively.

The administration of $10 \mathrm{mg} / \mathrm{kg}$ COC also increased both caudate and accumbens DA. However, although COC promoted levels of crossover activity substantially greater than $0.5 \mathrm{mg} / \mathrm{kg}$ AMPH (Table 2), the magnitudes of the increases in both caudate and accumbens DA were markedly less than was obtained following AMPH. In response to COC, DA increased to $70 \mathrm{nM}$ in caudate and $62 \mathrm{nM}$ in accumbens $(370 \%$ and $470 \%$ of baseline, respectively). Also in contrast to $\mathrm{AMPH}$, this dose of $\mathrm{COC}$ had little effect on caudate DOPAC or HVA concentrations, but significantly decreased accumbens DOPAC and HVA to about $75 \%$ of predrug baseline concentrations.

Similar to COC, and in contrast to AMPH, $1.7 \mathrm{mg} / \mathrm{kg} \mathrm{FCF}$ increased caudate and accumbens DA to 61 and $48 \mathrm{~nm}$ in these two regions $(270 \%$ and $360 \%$ of baseline, respectively). In addition, like $10 \mathrm{mg} / \mathrm{kg} \mathrm{COC}$, this dose of FCF had no effect on caudate DOPAC or HVA concentrations, but significantly decreased accumbens concentrations of DOPAC and HVA by about $25 \%$. The caudate and accumbens DA responses to these

Table 2. Locomotor response to low-dose stimulant administration

\begin{tabular}{lllccc} 
& \multicolumn{5}{c}{ Crossovers (mean \pm SEM) } \\
\cline { 4 - 6 } Stimulant & $($ Dose $)$ & $(n)$ & $0-60 \min$ & $60-120 \mathrm{~min}$ & $0-120 \mathrm{~min}$ \\
\hline AMPH & $(0.5 \mathrm{mg} / \mathrm{kg})$ & $(7)$ & $71 \pm 12$ & $18+6$ & $89+16$ \\
COC & $(10 \mathrm{mg} / \mathrm{kg})$ & $(7)$ & $228 \pm 76^{*}$ & $17 \pm 9$ & $246 \pm 81^{* *}$ \\
FCF & $(1.7 \mathrm{mg} / \mathrm{kg})$ & $(5)$ & $182 \pm 33^{*}$ & $43 \pm 6^{*}$ & $224 \pm 32^{* *}$
\end{tabular}

Significantly different from corresponding AMPH values using $t$ test with Bonferroni correction following significant

ANOVA: ${ }^{*}, p<0.05 ; * *, p<0.01$. 

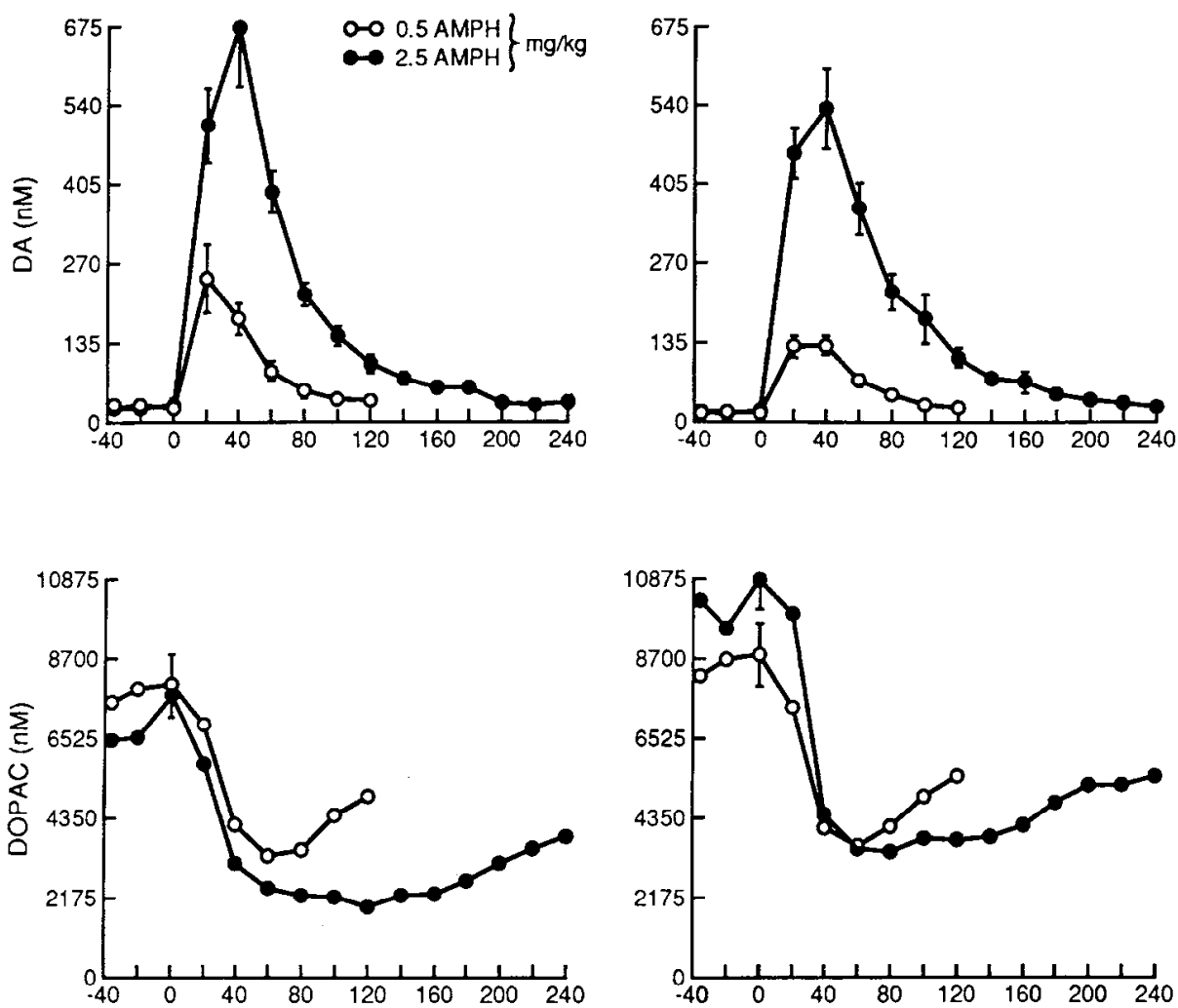

Figure 2. Caudate and accumbens dopaminergic response to AMPH. Groups of rats ( $n=7$ each) received either 0.5 or $2.5 \mathrm{mg} / \mathrm{kg}$ AMPH.
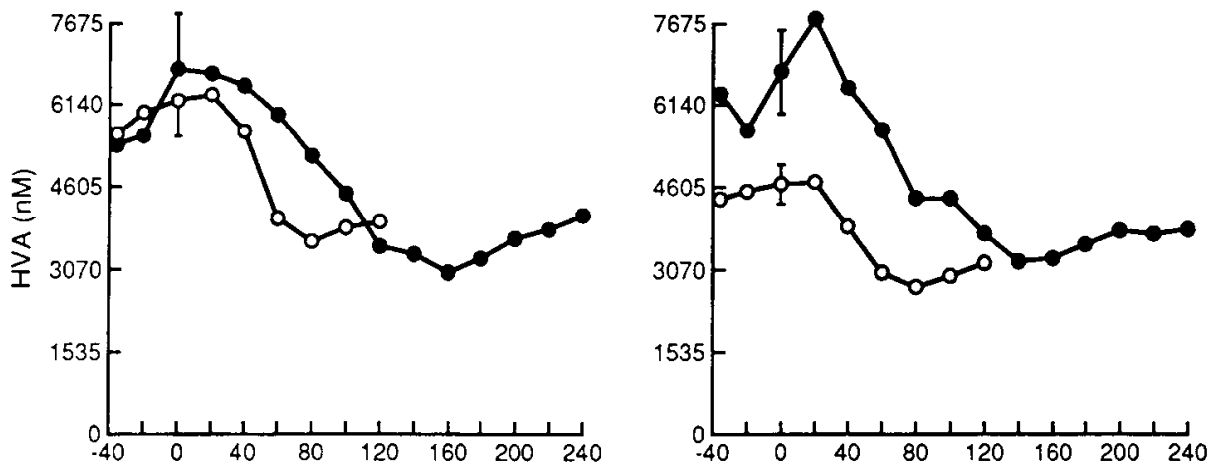

Time Relative to Injection (min)

three drugs in time intervals comparable to the behavioral data in Table 2 are presented in Table 3.

\section{Response to high dose of stimulants}

The higher doses of AMPH (2.5 mg/kg), COC (40 mg/kg), and FCF $(6 \mathrm{mg} / \mathrm{kg}$ ) were selected because they promoted a qualitatively similar multiphasic response pattern including an initial period of enhanced crossover activity, followed by a prolonged period during which animals engaged in intense focused stereotypies. The initial locomotor response $(0-40 \mathrm{~min})$ following drug administration is summarized in Table 4, and the stereotypy response profiles are presented in Figure 5 . Following $2.5 \mathrm{mg}$ / $\mathrm{kg} \mathrm{AMPH}$ or $6 \mathrm{mg} / \mathrm{kg} \mathrm{FCF}$, the stereotypy phase (40-120 min) consisted predominantly of oral behaviors and some repetitive head movements (Fig. 5). In contrast, with COC $(40 \mathrm{mg} / \mathrm{kg})$ repetitive movements were the prevailing form of stereotypy.

Consistent with previous results, $2.5 \mathrm{mg} / \mathrm{kg}$ AMPH increased caudate DA nearly 30 -fold (2930\%) to $675 \mathrm{~nm}$ and decreased DOPAC and HVA to $30 \%$ and $50 \%$, respectively, of predrug values. Similarly, AMPH increased accumbens DA nearly 30 fold $(3110 \%)$ to $510 \mathrm{nM}$ and decreased DOPAC and HVA to $38 \%$ and $60 \%$ of baseline. In both brain regions, peak DA concentrations were achieved during the initial 20-40 min and then rapidly declined.

As was observed following the lower stimulant doses, the caudate and accumbens DA responses to $40 \mathrm{mg} / \mathrm{kg}$ COC or 6 $\mathrm{mg} / \mathrm{kg}$ FCF were substantially less than the response to AMPH. Indeed, the DA responses to these high doses of COC and FCF 
Caudate-Putamen
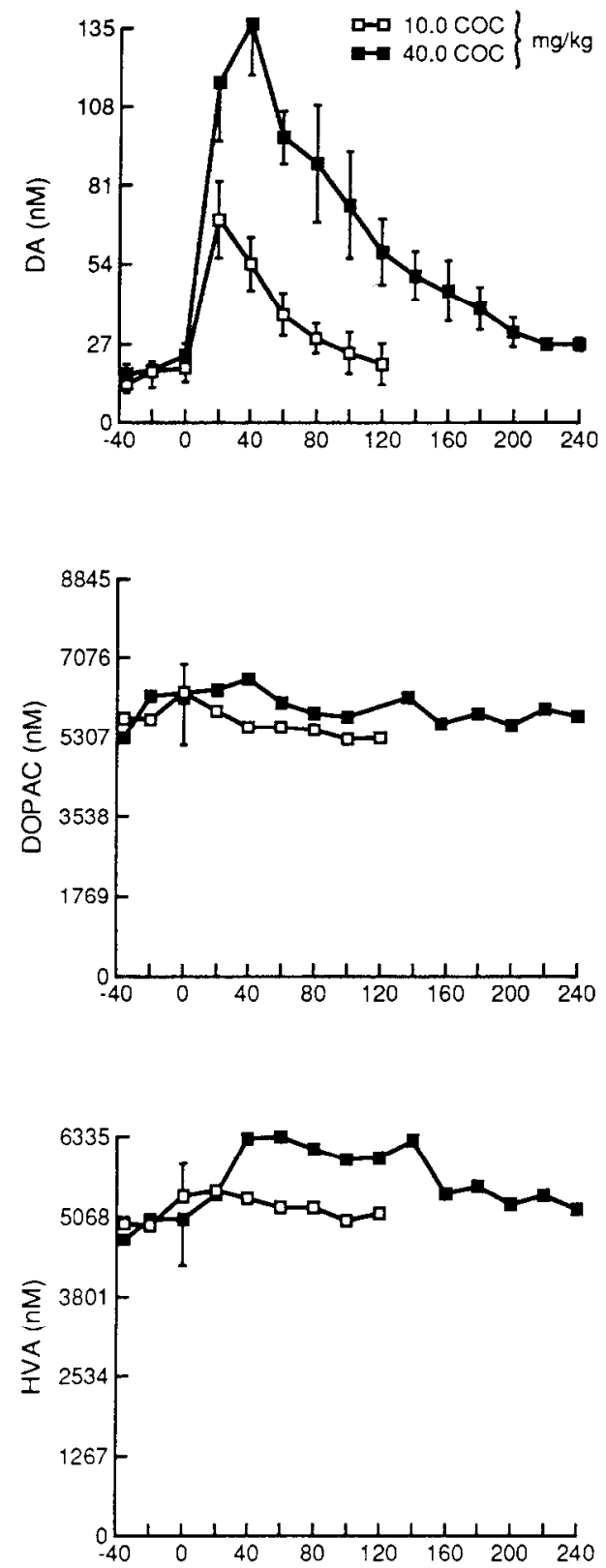

Time Relative to Injection (min)

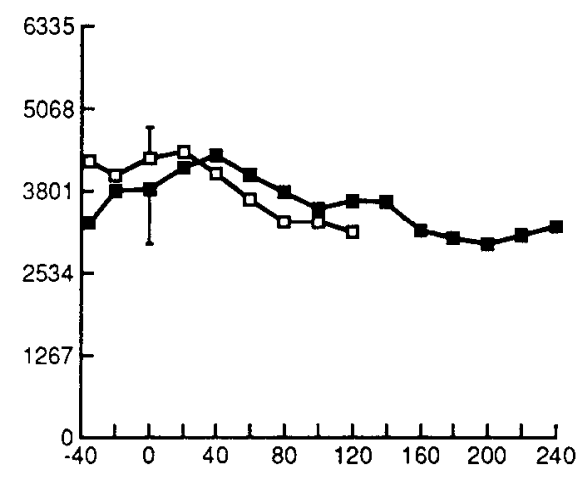

Nucleus Accumbens
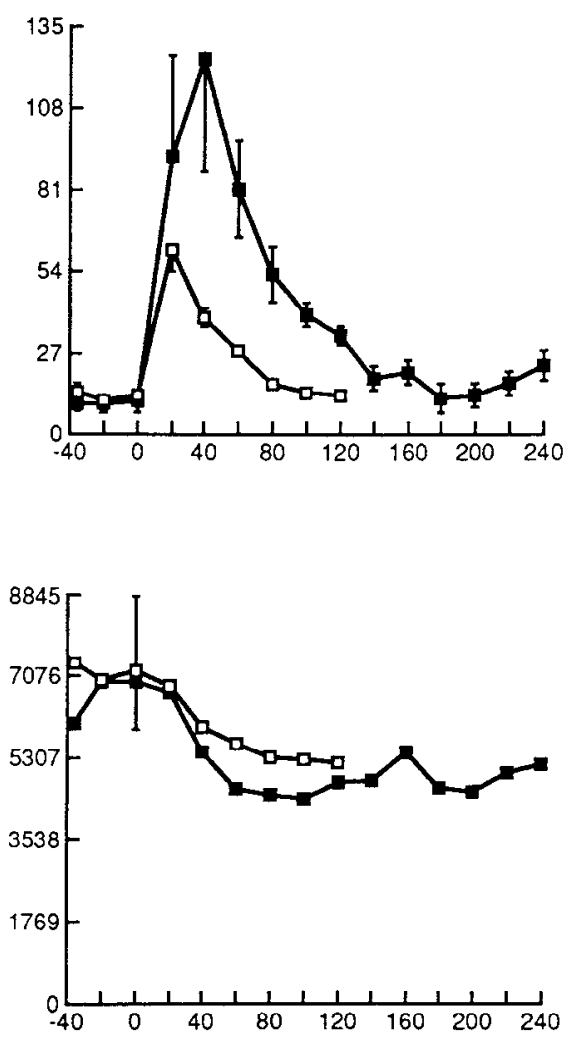

Figure 3. Caudate and accumbens dopaminergic response to $\mathrm{COC}$. Rats were administered either $10 \mathrm{mg} / \mathrm{kg}(n=7)$ or $40 \mathrm{mg} / \mathrm{kg}(n=8) \mathrm{COC}$.

Table 3. Dopaminergic response to low-dose stimulant administration

\begin{tabular}{llllllc}
\multicolumn{9}{c}{ Area under curve (nM/60 min) } \\
\cline { 4 - 7 } Stimulant & $($ Cose $)$ & $(n)$ & $0-60 \mathrm{~min}$ & $60-120 \mathrm{~min}$ & $0-60 \mathrm{~min}$ & $60-120 \mathrm{~min}$ \\
\hline AMPH & $(0.5 \mathrm{mg} / \mathrm{kg})$ & $(7)$ & $502 \pm 95$ & $124 \pm 25$ & $334 \pm 42$ & $104 \pm 17$ \\
COC & $(10 \mathrm{mg} / \mathrm{kg})$ & $(7)$ & $162 \pm 30^{* *}$ & $76 \pm 20$ & $130 \pm 8^{* *}$ & $45 \pm 1^{* *}$ \\
FCF & $(1.7 \mathrm{mg} / \mathrm{kg})$ & $(5)$ & $160 \pm 21^{* *}$ & $134 \pm 16$ & $101 \pm 12^{* *}$ & $62 \pm 6^{*}$
\end{tabular}

Significantly different from corresponding AMPH values: ${ }^{*}, p<0.05 ;{ }^{* *}, p<0.01$. Between-group comparisons were made using $t$ tests with Bonferroni correction following significant ANOVA. 
Caudate-Putamen
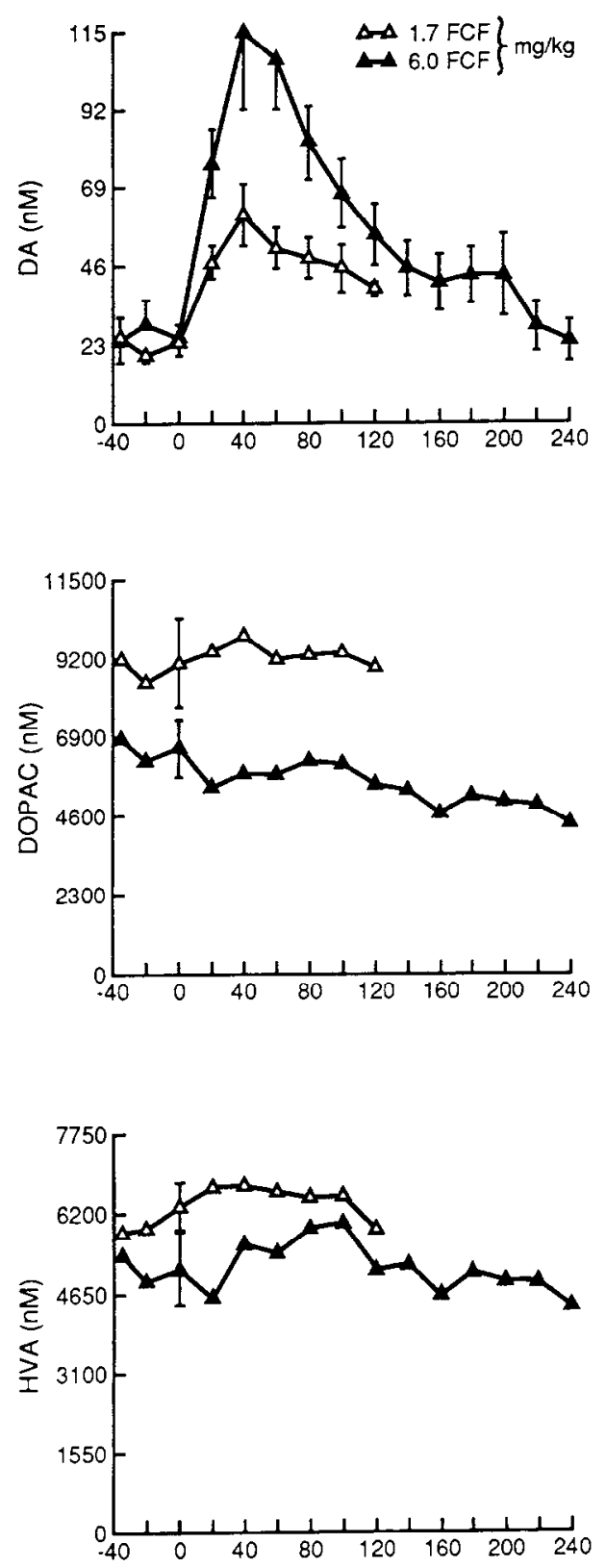

Nucleus Accumbens
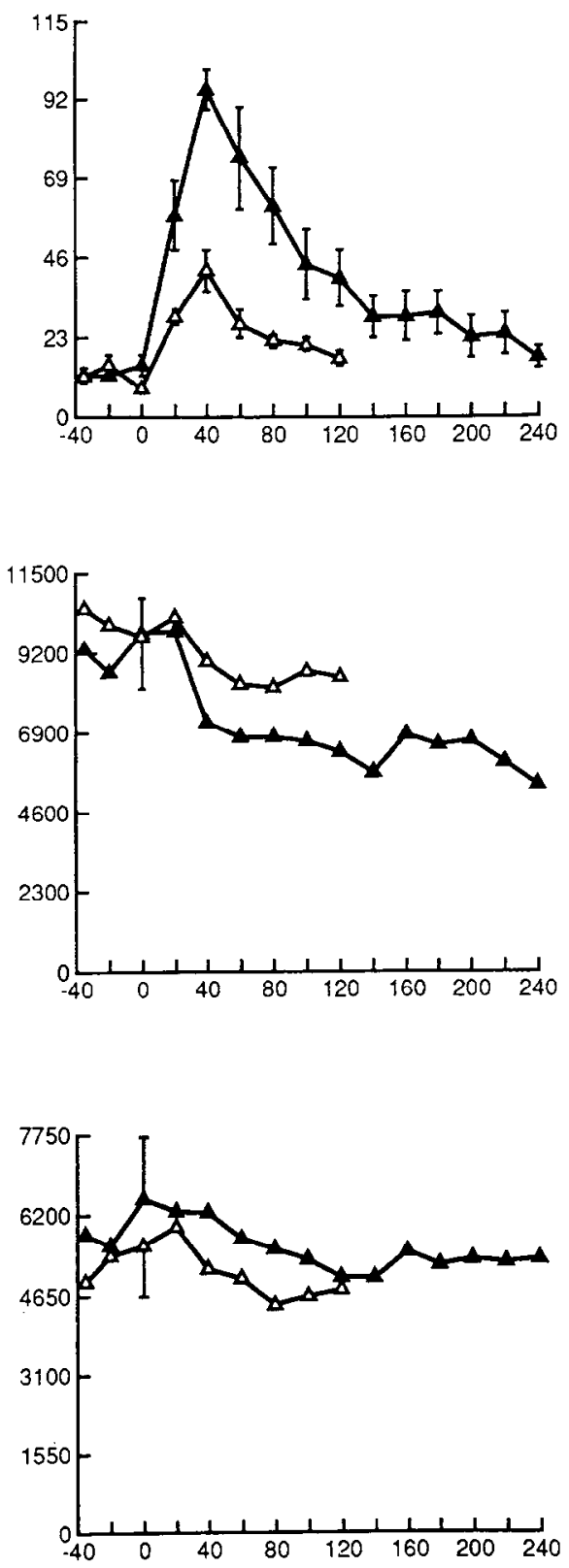

Figure 4. Caudate and accumbens dopaminergic response to FCF. Rats were administered either $1.7 \mathrm{mg} / \mathrm{kg}(n=5)$ or $6.0 \mathrm{mg} / \mathrm{kg}(n=8) \mathrm{FCF}$.

Time Relative to Injection (min)

were less than the response to $0.5 \mathrm{mg} / \mathrm{kg} \mathrm{AMPH}$ in both caudate and accumbens. COC increased DA to $138 \mathrm{~nm}$ in caudate and to $124 \mathrm{~nm}$ in accumbens ( $730 \%$ and $1170 \%$ of baseline), each about $20 \%$ of the maximal response observed following $2.5 \mathrm{mg} /$ $\mathrm{kg}$ AMPH. Similarly, FCF increased DA to $112 \mathrm{nM}$ in caudate and $96 \mathrm{~nm}$ in accumbens ( $550 \%$ and $840 \%$ of baseline). In addition, both FCF and COC promoted region-specific changes in the metabolite profiles, although the magnitude of these changes, in contrast to AMPH, was small. Neither FCF nor COC at the high doses affected caudate DOPAC. Both drugs increased caudate HVA by about $20 \%$, but only the COC-induced increase achieved statistical significance. At the same time, in accumbens, both drugs at the high dose significantly decreased DOPAC by nearly $35 \%$, but had little effect on HVA.

\section{Discussion}

To assess the relative contribution of caudate and accumbens DA release to the various features of the psychostimulant behavioral response, doses of $\mathrm{AMPH}, \mathrm{COC}$, and FCF were chosen to promote either enhanced locomotion or a multiphasic pattern including a period of continuous focused stereotypies. Consistent with our earlier results utilizing the microdialysis technique, each of these psychostimulants produced a dose-dependent enhancement of extracellular dopamine in both caudate and accumbens. The magnitude and temporal characteristics of the DA responses to AMPH in both caudate and accumbens are consistent with previous reports (Zetterström et al., 1986; Hernandez et al., 1987; Sharp et al., 1987; Carboni et al., 1989; 
Kuczenski and Segal, 1989; Robinson and Camp, 1990). COC also promoted a dose-dependent increase in both caudate and accumbens DA, and the qualitative and quantitative features of the DA response are generally in agreement with the findings of others (Bradberry and Roth, 1989; Carboni et al., 1989; Kalivas and Duffy, 1990). FCF, which, like COC, is reputed to facilitate dopaminergic transmission primarily through uptake blockade, produced COC-like DA changes.

The profound disparity in extracellular DA among the three stimulants at behaviorally similar doses suggests the absence of a simple relationship between the quantitative features of the dopaminergic response and both the quantitative and qualitative characteristics of the stimulant-induced behavioral profiles. Additionally, despite marked dose-related behavioral differences, the ratio of the DA responses in the two regions did not differ as a function of dose for any of the three drugs.

We have previously detailed the apparent dissociation between the quantitative features of the nigrostriatal DA response to AMPH and the appearance of specific stereotypy components (Kuczenski and Segal, 1989, 1990). The present results indicate that this quantitative dissociation also applies to the mesolimbic DA system and is most evident with respect to the temporal features of the neurochemical and behavioral profiles. Thus, whereas stereotypies were maintained at up to 100 min following $2.5 \mathrm{mg} / \mathrm{kg}$ AMPH, both caudate and accumbens DA declined more than fivefold over this interval. The stereotypy responses to COC and FCF were also temporally dissociated from the DA responses in both caudate and accumbens. That is, extracellular DA peaked in both accumbens and caudate at $20-40 \mathrm{~min}$ following the administration of either $40 \mathrm{mg} / \mathrm{kg}$ COC or $6 \mathrm{mg} / \mathrm{kg}$ FCF, and then rapidly declined. In contrast, focused stereotypies persisted for nearly $100 \mathrm{~min}$ following these drugs.

Additionally, a comparison of the relative dopaminergic and stereotypy responses between AMPH and FCF provides further evidence for the behavioral/dopaminergic dissociation. Accordingly, $6.0 \mathrm{mg} / \mathrm{kg}$ FCF promoted intense focused stereotypies qualitatively and quantitatively similar to $2.5 \mathrm{mg} / \mathrm{kg} \mathrm{AMPH}$. In contrast, the extracellular DA concentrations in both caudate and accumbens were dramatically less after FCF than following AMPH administration. In fact, maximal DA concentrations occurring at the onset of intense oral stereotypy in response to $6 \mathrm{mg} / \mathrm{kg}$ FCF were less than DA concentrations observed following $0.5 \mathrm{mg} / \mathrm{kg}$ AMPH. These observations support our earlier contention that the appearance of stereotyped behaviors in response to psychostimulant administration is not solely dependent on the quantitative features of the caudate or accumbens DA response.

Our findings also suggest the absence of a simple relationship between the magnitude of locomotor activation and extracellular concentrations of either caudate or accumbens DA. First,
$\%$ Time in Stereotypy
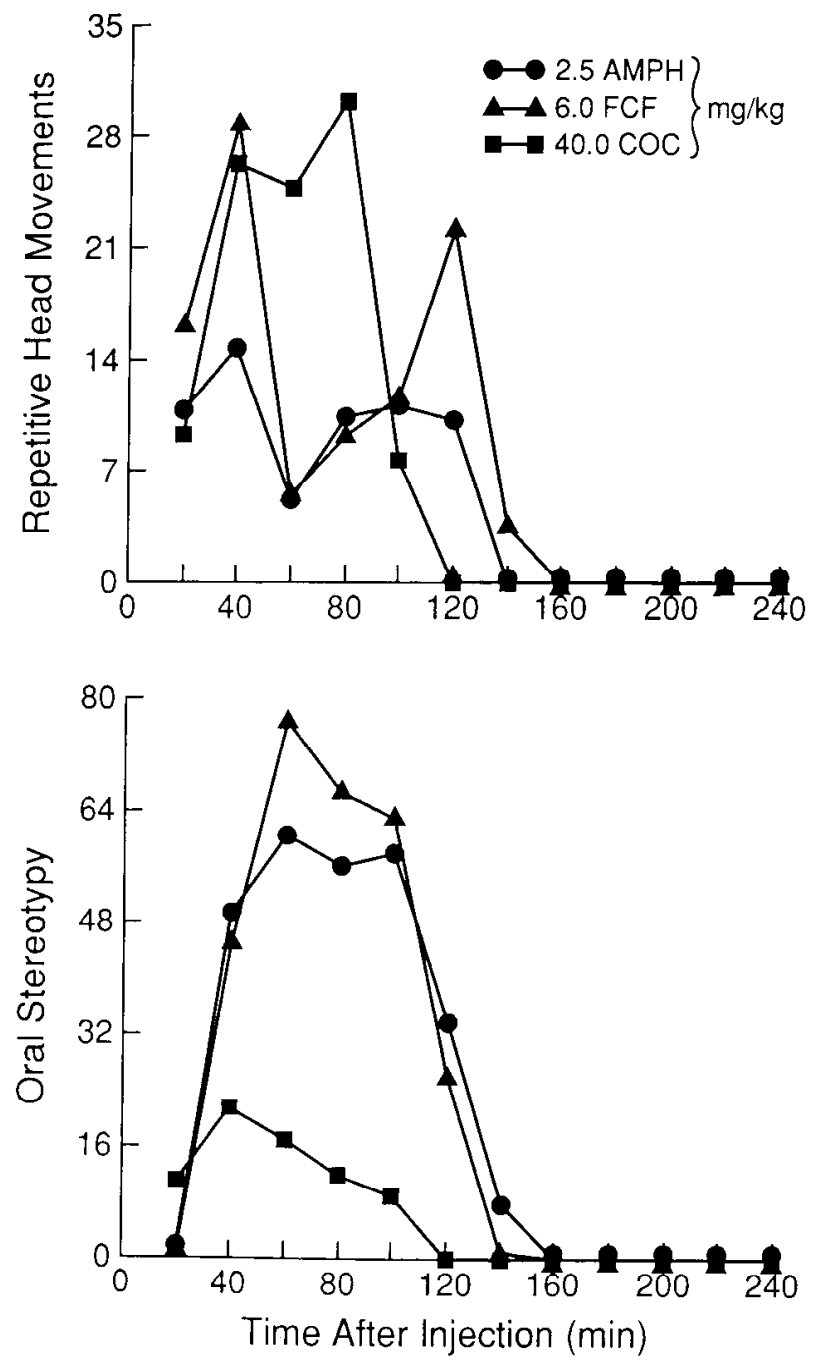

Figure 5. Temporal pattern of stereotypy response to AMPH, COC, and FCF of animals undergoing concomitant caudate and accumbens dialysis. Stereotypy is presented as percentage of total time spent in repetitive head movements or oral behaviors.

despite the fact that $0.5 \mathrm{mg} / \mathrm{kg}$ AMPH produced significantly lower levels of locomotion than did $10 \mathrm{mg} / \mathrm{kg}$ COC or $1.7 \mathrm{mg} /$ $\mathrm{kg} \mathrm{FCF}$, this dose of AMPH promoted a nearly fivefold greater DA response in both caudate and accumbens than did either COC or FCF. It is conceivable that, in contrast to the more continuous DA release induced by AMPH, the increase in extracellular DA produced by the uptake blockers fluctuates as a

Table 4. Initial (0-40 min) locomotor and dopaminergic responses to high-dose stimulant administration

$\begin{array}{llllll} & & & & \text { Area under curve } \\ \text { Stimulant } & (\text { Dose }) & (n) & \text { Crossovers } & \text { Caudate DA } & 1176 \pm 148 \\ \text { AMPH } & (2.5 \mathrm{mg} / \mathrm{kg}) & (7) & 176 \pm 21 & 254 \pm 40^{* * *} & 993 \pm 107 \\ \text { COC } & (40 \mathrm{mg} / \mathrm{kg}) & (8) & 100 \pm 50 & 192 \pm 32^{* * *}\end{array}$

***, Significantly different from corresponding AMPH values $(p<0.001)$. Between-group comparisons were made using $t$ tests with Bonferroni correction following a significant ANOVA. 
function of neuronal activity. Such a pattern of reccptor activation might be more functionally effective in inducing behavioral change. However, it seems more likely that, as with AMPH, uptake blockers produce a monotonic increase in synaptic DA. Therefore, differences in the pattern of DA release would not be reflected in differences in the pattern of receptor activation and thus would not account for the dissociation between DA concentrations and behavior for the different stimulants.

Second, each stimulant promoted a locomotor pattern that was temporally dissociated from the DA response. That is, for all three stimulants, maximal locomotor activation occurred during the initial 10-20 min following drug administration and declined more rapidly than did extracellular DA. For example, following $0.5 \mathrm{mg} / \mathrm{kg} \mathrm{AMPH}$, crossovers during the second 20 min interval were $60 \%$ of the first 20 min interval, whereas accumbens DA was $102 \%$ of the first interval. Similarly, the relative crossover and accumbens DA values for the same intervals following FCF were $50 \%$ and $143 \%$, and following COC, were $23 \%$ and $63 \%$. Thus, the locomotor and DA responses were not parallel. Therefore, to the extent that dialysate levels of DA provide an accurate reflection of synaptic transmitter dynamics, our results provide compelling evidence that the qualitative and quantitative features of the stimulant-induced response profile are not strictly related to the caudate and/or accumbens extracellular concentrations of DA. It should be acknowledged, however, that these brain regions are anatomically and functionally heterogeneous. Thus, a dopaminergic response in other subregions more closely paralleling the stimulant behavioral profile might predominate in the expression of specific behavioral components. However, our exploratory studies to test this hypothesis have not revealed remarkable regional variations in the DA response profile.

The neurochemical profiles produced by the threc stimulants in the two brain regions exhibited both common and distinguishing features. First, the DOPAC and HVA responses to AMPH were parallel in the caudate and accumbens. These results suggest that similar mechanisms govern the dynamics of the response of DA metabolism to AMPH in both brain regions. That is, as has been suggested for the caudate, the predominant fraction of DOPAC and HVA in accumbens appears to derive from the metabolism of excess intraneuronal DA. Partial depletion of cytoplasmic DA resulting from AMPH-induced DA release may be largely responsible for the decline in DOPAC concentrations (Zetterström et al., 1986; Kuczenski and Segal, 1989; Kuczenski et al., 1990). However, the decline is dissociated from synaptic DA concentrations because the response of various regulatory and compensatory components, including DA synthesis and vesicular-cytoplasmic equilibria, may contribute to alleviate continucd deplction (Zetterström et al., 1983, 1986; Callaway et al., 1989; Kuczenski and Segal, 1989; Manley et al., 1990).

COC and FCF produced region-specific effects on DOPAC and HVA that contrasted with AMPH. For one, neither COC nor FCF affected caudate DOPAC, providing additional evidence that stimulant-induced changes in DOPAC are dissociated from changes in synaptic DA. Thal is, since both drugs increased extracellular DA (presumably through uptake blockade), a decrease in DOPAC should have occurred if released transmitter comprises a significant portion of DOPAC formation. Furthermore, this increased extracellular DA derives from the vesicular DA pool, which is, in turn, presumably equilibrated with cytoplasmic transmitter. To the extent that DOPAC reflects cytoplasmic DA dynamics, the absence of a change in this metabolite following uptake blockade would indicate that caudate DA synthesis is maintained at a sufficient pace to conserve this pool.

Also in contrast to AMPH, which substantially decreases caudate HVA in parallel with DOPAC, both COC and FCF tended to increase caudate dialysate HVA concentrations. Parallel changes in DOPAC and HVA would be expected since HVA is a second metabolite of DA (Westerink, 1985) that is usually primarily derived from the action of catechol-O-methyl transferase (COMT) on DOPAC. The increase in HVA in the absence of significant changes in DOPAC suggests that uptake blockers shift the route of inactivation of released DA from uptake into the nerve terminal, to extraneuronal metabolism via COMT. Likewise, although most doses of AMPH decrease HVA concentrations in parallel with DOPAC, we have previously noted that at higher AMPH doses, DA metabolism also appears to be shifted to the extraneuronal pathway, presumably reflecting uptake inhibition by this drug as well (Kuczenski, 1980, 1983).

DA metabolism in accumbens appears to respond to the uptake blockers differently than in caudate. In contrast to the lack of effect of COC and FCF on caudate DOPAC, both uptake inhibitors significantly decreased accumbens DOPAC by approximately $30 \%$ from predrug concentrations. Kalivas and Duffy (1990) also noted a decline in accumbens DOPAC following COC. This effect on accumbens DOPAC might suggest that a significant portion of DOPAC formation in this DA terminal field derives from the uptake and metabolism of released transmitter. However, comparison of the DA and DOPAC temporal response patterns indicates that other factors must contribute as well. That is, DOPAC concentrations continued to decline long after maximal extracellular DA concentrations were achicved. Thus, as was apparent for caudate, a simple relationship between accumbens DOPAC concentrations and extracellular DA is not evident. However, the decline in accumbens DOPAC in response to uptake blockade, in contrast to the lack of caudate response, implies some regional differences in factors regulating DA dynamics. For example, the accumbens cytoplasmic DA pool, and consequently levels of accumbens DOPAC, may be more susceptible to depletion, reflecting either less biosynthetic reserve or a more effective control of DA synthesis resulting from DA interaction with nerve terminal autoreceptors.

Also in contrast to caudate, accumbens HVA concentrations tended to parallel the decline in DOPAC concentrations. That is, in spite of the substantial increase in extracellular DA, the shift to extraneuronal metabolism that is anticipated as a consequence of uptake blockade was not apparent in the accumbens. Thcsc data are consistent with previous suggestions (Westerink and Korf, 1976; Robinson and Camp, 1990) that the metabolism of DA through COMT proceeds at a lower rate in accumbens than in caudate. The substantially higher DOPAC-to-HVA ratio in accumbens as compared to caudate (Table 1 ) is also consistent with this suggestion. Furthermore, we have recently observed (Kuczenski and Segal, unpublished observations) that baseline dialysate concentrations of 3-methoxytyramine occur at about $50 \%$ of DA concentrations in caudate, but only at about $20 \%$ of DA concentrations in accumbens.

Such differences in caudate and accumbens DA dynamics may be enhanced in the presence of uptake blockers and, more importantly, could underlie differential regional dopaminergic responses to uptake blockade. For example, since blockade of 
presynaptic uptake restricts the metabolism of released DA to extraneuronal COMT and monamine oxidase (MAO), a lower level of COMT activity could prolong DA synaptic duration in accumbens relative to caudate. Additionally, the level of impulse flow appears to be greater in mesolimbic as compared to mesostriatal DA neurons (Chiodo, 1988). Since the degree of enhancement of synaptic DA by uptake blockade will be proportional to the amount of transmitter released by impulse traffic, these drugs should produce a relatively greater DA effect in accumbens as compared to caudate. In fact, in spite of the lower baseline concentration of DA in accumbens, maximal absolute accumbens DA concentrations approached maximal caudate DA concentrations in response to FCF or COC (Fig. 3, 4). Likewise, when the maximal DA responses in the two regions are expressed as a percentage of baseline, the accumbens-to-caudate ratio for the uptake blockers (accumbens: caudate $=1.30 \pm$ $0.10)$ is significantly higher $(p<0.01)$ than for AMPH (accumbens : caudate $=0.99 \pm 0.15$ ). These observations are consistent with a greater accumbens response to uptake blockade, and regional differences in COMT activity and levels of impulse traffic may be responsible.

In contrast, impulse-independent DA release, and not blockade of DA uptake, appears to be the predominant mechanism underlying AMPH-DA interactions. Although Di Chiara and co-workers originally reported that all indirectly acting DA stimulants, including AMPH, more effectively increase extracellular DA in accumbens as compared to caudate (Carboni et al., 1989), the weight of evidence (Sharp et al., 1987; Robinson and Camp, 1990) including our data (Fig. 2) indicates that with this drug the accumbens and caudate DA responses are not differentiated.

In assessing these results and dialysis data in general, it is important to note that some uncertainty still remains regarding their interpretation. For example, the extracellular transmitter pool sampled by dialysis likely reflects only a fraction of synaptic transmitter and not the actual concentration required to trigger receptor-mediated postsynaptic events (Gonon, 1988). Thus, that dialysate DA fluctuates in parallel with released DA remains speculative. However, a variety of converging evidence supports the assumption that this extracellular pool provides an accurate index of released DA. For one, dialysate DA is $\mathrm{Ca}^{2+}$ dependent and tetrodotoxin sensitive, supporting the idea that the transmitter derives from impulse-dependent release (Imperato and Di Chiara, 1984; Westerink et al., 1989). Consistent with that suggestion, manipulations that decrease impulse flow, such as the administration of DA receptor agonists like apomorphine (Zetterström and Ungerstedt, 1984; Imperato et al., 1988; Kuczenski et al., 1990), or that decrease the a vailability of vesicular DA, such as reserpine pretreatment (Butcher et al., 1988; Callaway et al., 1989), also decrease extracellular DA. Conversely, direct electrical stimulation of the nigrostriatal DA pathway results in a frequency-dependent increase in caudate extracellular DA, in both the absence and presence of a DA-uptake blocker (Manley et al., 1990). In addition, nonpharmacological manipulations, such as the presentation of stressors (Abercrombie et al., 1989; Imperato et al., 1989; Pei et al., 1990) or food reward (Hernandez and Hocbel, 1988) have been shown to alter extracellular DA in a predictable fashion, suggesting that the detection of changes in synaptic DA does not require a druginduced perturbation. With respect to the specific stimulants used in the present studies, the effects of both AMPH and COC on extracellular DA are consistent with the presumed mechanisms of action of these two agents. Thus, at the present time, the available evidence supports the assumption that the dopaminergic response assessed in microdialysates provides a reasonable estimate of synaptic DA dynamics. Therefore, although caution should be exercised in the interpretation of dialysis results, our data indicate that a dissociation exists between the behavioral response to stimulants and the quantitative features of the caudate and accumbens DA responses, and that other neurochemical systems and mechanisms are implicated.

\section{References}

Abercrombie ED, Keefe KA, DiFrischia DS, Zigmond MJ (1989) Differential effect of stress on in vivo dopamine release in striatum, nucleus accumbens, and medial frontal cortex. J Neurochem 52:16551658.

Benveniste H, Hansen AI, Ottosen NS (1989) Determination of brain interstitial concentrations by microdialysis. J Neurochem 52:17411750.

Bradberry CW, Roth RH (1989) Cocaine increases extracellular dopamine in rat nucleus accumbens and ventral tegmental area as shown by in vivo microdialysis. Neurosci Lett 103:97-102.

Butcher SP, Fairbrother IS, Kelly JS, Arbuthnott GW (1988) Amphetamine-induced dopamine release in the rat striatum: an in vivo microdialysis study. J Neurochem 50:346-355.

Callaway CW, Kuczenski R, Segal DS (1989) Reserpine enhances amphetamine stereotypies without increasing amphetamine-induced changes in striatal dialysate dopamine. Brain Res 505:83-90.

Carboni E, Imperato A, Perezzani L, Di Chiara G (1989) Amphetamine, cocaine, phencyclidine and nomifensine increase extracellular dopamine concentrations preferentially in the nucleus accumbens of freely moving rats. Neuroscience 28:653-661.

Chiodo LA (1988) Dopamine-containing neurons in the mammalian central nervous system: electrophysiology and pharmacology. Neurosci Biobehav Rev 12:49-91.

Church WH, Justice JB (1987) Rapid sampling and determination of extracellular dopamine. Anal Chem 59:712-716.

Cole SO (1978) Brain mechanisms of amphetamine-induced anorexia, locomotion, and stereotypy: a review. Neurosci Biobehav Rev 2:89100

Creese I, Iversen SD (1974) The role of forebrain dopamine systems in amphetamine-induced stereotypy in the adult rat following neonatal treatment with 6-hydroxydopamine. Psychopharmacology 39: 345-357.

DeI ucia R, Bernardi MM, Scavone C, Aizenstein M (1984) On the mechanism of central stimulation action of fencamfamine. Gen Pharmacol 15:407-410.

Gonon FG (1988) Non-linear relationship between impulse flow and dopamine released by rat midbrain dopaminergic neurons as studied by in vivo electrochemistry. Neuroscience 24:19-28.

Hernandez L, Hoebel BG (1988) Food reward and cocaine increase extracellular dopamine in the nucleus accumbens as measured by microdialysis. Life Sci 42:1705-1712.

Hernandez L, Lee F, Hoebel BG (1987) Simultaneous microdialysis and amphetamine infusion in the nucleus accumbens and striatum of freely moving rats: increase in extracellular dopamine and serotonin. Brain Res Bull 19:623-628.

Imperato A, Di Chiara G (1984) Trans-striatal dialysis coupled to reverse phase high performance liquid chromatography with electrochemical detection: a new method for the study of the in vivo release of endogenous dopamine and metabolites. J Neurosci 4:966-977.

Impcrato A, Tanda G, Frau R, Di Chiara G (1988) Pharmacological profile of dopamine receptor agonists as studied by brain dialysis in behaving rats. J Pharmacol Exp Ther 245:257-264.

Imperato A, Puglisi-Allegra S, Casolini P, Zocchi A, Angelucci L (1989) Stress-induced enhancement of dopamine and acetylcholine release in limbic structures: role of corticosterone. Eur J Pharmacol 165:337338.

Kalivas PW, Duffy P (1990) Effect of acute and daily cocaine treatment on extracellular dopamine in the nucleus accumbens. Synapse 5:4858.

Kelly P, Iversen SD (1976) Seclective 60HDA-induced destruction of mesolimbic dopamine neurons: abolition of psychostimulant-induced locomotor activities in rats. Eur J Pharmacol 40:45-56.

Kelly PH (1977) Drug-induced motor behavior. In: Handbook of 
psychopharmacology (Iversen LL, Snyder SH, eds), pp 295-311. New York: Raven.

Kuczenski R (1980) Amphetamine-haloperidol interactions on striatal and mesolimbic tyrosine hydroxylase activity and dopamine metabolism. J Pharmacol Exp Ther 215:135-142.

Kuczenski R (1983) Biochemical actions of amphetamine and other stimulants. In: Stimulants: neurochemical, behavioral, and clinical perspectives (Creese I, ed), pp 31-61. New York: Raven.

Kuczenski R, Segal DS (1989) Concomitant characterization of behavioral and striatal neurotransmitter response to amphetamine using in vivo microdialysis. J Neurosci 9:2051-2065.

Kuczenski R, Segal DS (1990) In vivo measures of monoamines during amphetamine-induced behaviors in rats. Prog Neuropsychopharmacol Biol Psychiatry 14:S37-S50.

Kuczenski R, Segal DS, Manley LD (1990) Apomorpine does not alter amphetamine-induced dopamine release measured in striatal dialysates. J Neurochem 54:1492-1499.

Manley LD, Kuczenski R, Young SJ, Segal DS, Groves PM (1990) The effect of medial forebrain bundle (MFB) stimulation on striatal dopamine and serotonin release as measured by microdialysis. Soc Neurosci Abstr 16:234.

Nicolaysen LC, Justice JB Jr (1988) Effects of cocaine on release and uptake of dopamine in vivo: differentiation by mathematical modeling. Pharmacol Biochem Behav 31:327-335.

Paxinos G, Watson C (1986) The rat brain in stereotaxic coordinates. Sydney: Academic.

Pei Q, Zetterström T, Fillenz M (1990) Tail pinch-induced changes in the turnover and release of dopamine and 5-hydroxytryptamine in different brain regions of the rat. Neuroscience 35:133-138.

Robinson TE, Camp DM (1990) Does amphetamine preferentially increase the extracellular concentration of dopamine in the mesolimbic system of freely moving rats? Neuropsychopharmacology $3: 163$ 173.

Segal DS, Kuczenski R (1987) Individual differences in responsiveness to single and repeated amphetamine administration: behavioral characteristics and neurochemical correlates. J Pharmacol Exp Ther 242: 917-926.
Sessions G, Meyerhoff J, Kant GJ, Koob GF (1980) Effects of lesions of the ventral medial tegmentum on locomotor activity, biogenic amines and response to amphetamine in rats. Pharmacol Biochem Bchav 12:603-608.

Seyfried CA (1983) Dopamine uptake inhibiting versus dopamine releasing properties of fencamfamine: an in vitro study. Biochem Pharmacol 32:2329-2331.

Sharp T, Zetterström T, Ljungberg T, Ungerstedt U (1987) A direct comparison of amphetamine-induced behaviours and regional brain dopamine release in the rat using intracerebral dialysis. Brain Res 401:322-330.

Swerdlow NR, Vaccarino FJ, Amalric M, Koob GF (1986) The neural substrates for the motor-activating properties of psychostimulants: a review of recent findings. Pharmacol Biochem Behav 25:233-248.

Wages SA, Church WA, Justice JB (1986) Sampling considerations for on-line microbore liquid chromatography of brain dialysis. Anal Biochem 58:1649-1656.

Westcrink BHC (1985) Scquence and significance of dopamine metabolism in the rat brain. Neurochem Int 7:221-227.

Westerink BHC, Korf J (1976) Turnover of acid dopamine metabolites in striatal and mesolimbic tissue of the rat brain. Eur J Pharmacol 37:249-255.

Westerink BHC, Hofsteede RM, Tuntler J, de Vries JB (1989) Use of calcium antagonism for the characterization of drug-evoked dopamine release from the brain of conscious rats determined by microdialysis. J Neurochem 52:722-729.

Zetterström T, Ungerstedt U (1984) Effects of apomorphine on the in vivo release of dopamine and its metabolites, studied by brain dialysis. Eur J Pharmacol 97:29-36.

Zetterström T, Sharp T, Marsden CA, Ungerstedt U (1983) In vivo measurement of dopamine and its metabolites by intracerebral dialysis: changes after $d$-amphetaminc. J Ncurochem 41:1769-1773.

Zetterström T, Sharp T, Ungerstedt U (1986) Further evaluation of the mechanism by which amphetamine reduces striatal dopamine metabolism: a brain dialysis study. Eur J Pharmacol 132:1-9. 